\title{
Openwashing:
}

\section{A decoupling perspective on organizational transparency}

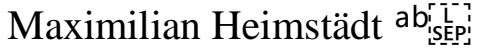 \\ ${ }^{a}$ Department of Management, Freie Universität Berlin \\ Boltzmannstraße 20, 14195 Berlin \\ m.heimstaedt@fu-berlin.de \\ ${ }^{\mathrm{b}}$ Reinhard Mohn Institute of Management, Witten/Herdecke University \\ Alfred-Herrhausen-Straße 15, 58455 Witten \\ maximilian.heimstaedt@uni-wh.de
}

Cite as:

Heimstädt, M. (2017). Openwashing: A decoupling perspective on organizational transparency. Technological Forecasting and Social Change, 125, 77-86. 


\begin{abstract}
With the rise of digital technologies, organizations are able to produce, process, and transfer large amounts of information at marginal cost. In recent years, these technological developments together with other macro-phenomena like globalization and rising distrust of institutions has led to unprecedented public expectations regarding organizational transparency. In this study I explore the ways in which organizations resolve the tension between a growing norm to share internal information with the public and their inherent preferences for informational control. Through developing the notion of transparency decoupling, I examine how organizations respond strategically to transparency expectations. Drawing on studies of "open data" transparency initiatives in NYC, London, and Berlin, I inductively carve out three modes of institutional information decoupling: (a) selecting the disclosed information to exclude parts of the data or parts of the audience; (b) bending the information in order to retain some control over its representative value; (c) orchestrating new information for a particular audience. The article integrates literature from New Institutional Theory and Transparency Studies in order to contribute to our understanding of how information sharing is realized in the interaction between organizations and their environment.
\end{abstract}

Keywords: Information sharing; transparency; secrecy; decoupling; open data 


\section{Introduction}

Recent developments in information technology have amplified demands for organizations to become more transparent. Being transparent is usually understood as sharing more information on internal operations (Albu \& Flyverbom, 2016). This trend towards information sharing and greater transparency has been discussed in regards to organizational phenomena like open innovation (Chesbrough, 2006), crowdsourcing (Bauer \& Gegenhuber, 2015) and most recently the sharing economy (Belk, 2014; Schor, Fitzmaurice, Carfagna, Attwood-Charles, \& Poteat, 2016). Although information sharing seems ubiquitous, what constitutes proper sharing turns out to be a highly contested issue. Users on blogs and social networks use the hashtag "\#openwashing" to report instances in which they disagree with an organization's claim of being transparent. Openwashing hence describes a mismatch between how the public expects information to be shared, and how an organization actually makes information available to the public ${ }^{1}$.

The rise of "public expectations regarding organizational transparency" (Wehmeier \& Raaz, 2012, p. 339) has oftentimes been linked to macro-phenomena like globalization, technological development and a growing distrust in formerly trusted institutions (Birkinshaw, 2006; Hood, 2006, 2007). Much has been written about the way in which transparency should best be implemented. Recently scholars have begun exploring how what is perceived to be "transparency" is enacted in practice (Neyland, 2007). For the organizational scholar, the performance of transparency becomes particularly intriguing, as sharing information is in conflict with the literature on organizational micro politics, which suggests that control over information is of great concern for managers and employees (Crozier \& Friedberg, 1980; Küpper \& Ortmann, 1988). Following a recent suggestion by Hansen and Flyverbom (2015) I turn to decoupling as an established instrument from institutional theory (Meyer \& Rowan, 1977; Westphal \& Zajac, 2001) in order to advance the nascent literature on performative transparency.

In order to elaborate on my theoretical understanding of decoupling as a solution to overcome conflicts between secrecy and transparency, I have conducted a

\footnotetext{
${ }^{1}$ In this study I interpret openness as an equivalent to transparency, informed by studies that have engaged more deeply with the technical-legal (Heimstädt, Saunderson, \& Heath, 2014) or socio-philosophical (Tkacz, 2012) discourses around the terms.
} 
longitudinal study on "open data" transparency initiatives in three large cities (NYC, London, and Berlin). Information that is disclosed through open data initiatives is oftentimes used to develop new commercial and non-commercial apps. Open data is thereby not only a transparency phenomenon, but at the same time lies within the sharing economy, an ecosystem that "uses information technologies to connect different stakeholders-individuals, companies, governments, and others - in order to make value by sharing their excess capacities [e.g. data sets] for products and services" (Laamanen, Pfeffer, Rong, \& Van De Ven, 2016, p. 218). To date, open data has received much less attention than the two-sided platforms (Zhu \& Iansiti, 2012) most commonly associated with the sharing economy, yet yields a particularly fruitful ground to study the paradoxical aspects of (information) sharing. Reconstructing episodes in which city agencies and external actors "enact transparency" (Hansen \& Flyverbom, 2015), I relied on media reports and interview data from the three large cities to answer the research question: How do organizations decouple compliance with the norm of transparency from their preferences for secrecy?

I identified three modes in which organizations decouple information sharing from their core operations. When selecting, organizations share authentic information, but exclude parts of it or share it with an exclusive audience. The two specific practices that emerged from my data are the distinction between sensitive and nonsensitive forms of information, and the distinction between admissible and inadmissible audiences for the information. When bending, organizations share authentic and comprehensive information, but in a form that deviates from the one used within the organization itself. Two distinct practices emerged from my data, the exploitation of situations of singularity and the exploitation of ambiguities in the articulated norms. When orchestrating, organizations share information that is modified in order to fit external expectations about its form and content. A particular practice of orchestrating I found is that organizations craft and publish new versions of existing data sets. My findings add to our understanding of transparency as policypractice or mean-end decoupling, as they show how organizations can turn the defensive strategy of decoupling into a tactical tool within their impression management repertoire. With an eye on the practical implications of this study, I 
eventually argue that some forms of institutionalized secrecy (e.g. those that avoid costly strategies of encryption and evasion), may in fact be in line with the goals of transparency advocates (e.g. increased productivity).

The remainder of this paper is organized as follows: I introduce my theoretical perspective on norms of transparency, organizational secrecy and decoupling as a lens to understand how actors resolve the tension that springs from their interplay. Then I explain in more detail my research setting, open data initiatives in NYC, London, and Berlin. I outline my methodological approach, methods of data collection, and data analysis. I present my findings on different practices and modes of transparency decoupling before discussing my contributions to the literature on decoupling as well as recent advances in the study of transparency as performance.

\section{Theoretical lens}

\subsection{The problematic nature of information sharing}

There are various lenses through which the "umbrella construct" (Hirsch \& Levin, 1999) of transparency can be studied. When studied as "disclosure", transparency can be defined as "the act of making new or previously secret information known" (Bernstein, 2016, p. 4). This definition resonates with Albu and Flyverbom (2016, p. 5) who have reviewed the transparency literature related to the study of organizations and found that "in most accounts, transparency is associated with the sharing of information". Over the past two decades there has been an unprecedented rise of "public expectations regarding organizational transparency" (Wehmeier \& Raaz, 2012, p. 339). Organizations of any kind found themselves confronted with the "widespread normative doctrine" (Hood, 2007, p. 193) of information sharing. Some authors even found transparency and information sharing being a "quasi-religious" dogma (Hood, 2006, p. 3) or framed as a "basic human right" (Birkinshaw, 2006). Political scientist Alon Peled aptly illustrates the normative claims for transparency as the constant promotion of an "imaginary world in which organizations and people happily and altruistically share data" (2011, p. 5).

Causalities for the rise of transparency expectations are manifold. Oftentimes the trend has been linked to macro-phenomena like globalization and a growing distrust in formerly trusted institutions, like governments or political parties (Ringel, 
2014). Further two amplifiers seem to be particularly powerful in the creation of a transparency norm: The mass media system and the proliferation of new information technologies. According to Curtin and Meijer (2006, p. 118) it is inherent to the mass media system that "failures sell better than successes". Therefore, they argue, media companies are particularly interested in and push for the release of information that organizations would prefer to keep covert in order to expose it as a "sign of irrationality or deviance" (Curtin \& Meijer, 2006, p. 118). On the other hand technological advances in the course of the 20th century have stimulated relentless demands for information sharing (Lord, 2007; Thompson, 2005). The more organizations ease the transmission of information by turning it into digital form, the more they stimulate the desire of external actors to get hold of it (Heimstädt, 2015).

The rise of a norm of information sharing and transparency raises questions about organizational responses. Do organizations act as "cultural dopes" (Powell \& Colyvas, 2008) and comply with it by opening up what has previously been closed? Or are they able to resist what they perceive as the public expectation? Studies that judge transparency by rather quantitative measures, e.g. the number of documents that have been released, come to the conclusion that organizations oftentimes give in to the external demands in order to restore their legitimacy. On an exemplary note, Tallberg (2016) argues that in recent years the growing political authority of international organizations (e.g. WTO, World Bank) has increased their need to legitimate their decision making process towards civil society (cf. Drucker \& Gumpert, 2007). If an international organization loses on public legitimacy, Tallberg argues, decision-making processes are likely to be disrupted, the completion of programs jeopardized and funding from member governments cut back. To prevent this from happening these organizations have offered access to documents and policymaking in order to strengthen legitimacy in relation to the external environment.

Despite a vast amount of literature from scientific authors (e.g. Chesbrough, 2006) and popular writers (e.g. Rifkin, 2015) about the advantages of sharing organizational information with the general public, organization theory has derived profound explanations why members of organizations would refrain from sharing information (Birchall, 2011; Hood \& Heald, 2006). Exemplary yet particularly revealing arguments that stress the problematic nature of information sharing come 
from classical bureaucratic theory and from literature on organizational micro politics. In an ideal typical bureaucratic organization, access to information is hierarchically organized. Employees are able to access information from lower levels within their chain of command (Weber, 1978). This arrangement secures the managerial authority by excluding workers from information on managerial decision-making processes. If, through any kind of transparency measures, this information is shared with the general public (including the workers), authority and therefore the guiding principle of the bureaucratic organization is under threat. Micro political theory complements this formal-hierarchical explanation of secrecy with an informal one (Burns, 1961; Crozier \& Friedberg, 1980). Not just in line, but also diagonal to the hierarchy, control over information channels can be a "source of power" to individuals (Küpper \& Ortmann, 1988). Forced to make the information they control accessible to the public and the other members of the organizations, individuals loose this power and thereby descend on the informal hierarchy. Recently Costas and Grey (2014, p. 1423) applied this micro political lens to the question of organizational secrecy, which they describe as the "ongoing formal and informal social processes of intentional concealment of information from actors by actors in organizations". In conclusion we can firmly assume that employees would try to avoid the release of information, although the transparency measure would result in the improvement of their informal or formal-hierarchical position through any other mechanism.

In this section I have opened up the research puzzle of organizational information sharing. On the one hand organizations are exposed to a steadily growing norm of transparency. Not complying with these norms threatens the general legitimacy of the organization. On the other hand organizational members have incentives to keep information closed in order to secure their position within formal and informal hierarchies. As Strathern (2000) puts it, there is "nothing innocent about making the invisible visible". Quite the contrary enacting organizational transparency seems to be a balancing act between legitimacy and power and social position. In the following section I propose decoupling as a theoretical lens that illustrates what organizations $d o$ when they do transparency (Neyland, 2007). 


\subsection{A decoupling perspective on information sharing}

The phenomenon of organizational information sharing is problematic. As Claire Birchall (2014) aptly puts it, we live in an age of transparency advocacy yet not necessarily in times of transparency. To this point, a lot of research has focused on how transparency should be achieved (Garsten \& Montoya, 2008) yet little attention has been paid to the question of how transparency is actually enacted in practice. Quite recently scholars began to bring together literature on transparency and information sharing (as outlined above) with well-established theories from organization studies, in order to foster cross-fertilization (Hansen, Christensen, \& Flyverbom, 2015). Hansen and Flyverbom (Hansen \& Flyverbom, 2015, p. 875 emphasis added) have suggested studying the problematic nature of organizational transparency as a case of decoupling, "whereby organizations project an image of being in control to the outside observer, whilst internal operations resist any meaningful connection to this image".

Based on the problematization described above, decoupling seems to be a fruitful perspective for understanding how organizations manage the mismatch between expected transparency and preferred secrecy. However, the concept needs to be updated with recent developments in decoupling theory and transparency research. Decoupling is a matured yet powerful tool for organizational analysis. The concept is grounded in the assumption that organizations adapt their formal structures to the institutionalized expectations they are exposed to in order to appear legitimate (Meyer \& Rowan, 1977). In some situations however, legitimate formal structures are in conflict with an organization's core operations. Most generally, decoupling can explain episodes in which organizations successfully create a facade of transparency by establishing legitimate institutional structures while simultaneously separating those structures from their operational core (Boxenbaum \& Jonsson, 2008; Scott, 1995). Westphal and Zajac (2001) specified these ideas and developed the concept of policy-practice decoupling, in which new policies are issued, but implemented, evaluated, and monitored so weakly that they hardly alter the day-to-day work routines (Tilcsik, 2010). In the case of information sharing implementation, it is not overly complex to implement from a technical standpoint, and we can expect that external stakeholders monitor implementation closely as information technology costs 
have reduced drastically. Policy-practice decoupling therefore seems still possible, yet not a sufficient instrument to capture all forms of decoupling. In a similar vein, Bromley and Powell (2012) have argued that in recent years the growing pressure on organizations to align their policies and practices has led to a new form of decoupling: that of means from ends. When engaged in mean-end decoupling, organizations do in fact change their practices according to the demands of their environment. Due to the increasing complexity of causal relationships in and around organizations, these new practices however do not lead to the outcomes the external stakeholders had in mind. Mean-end decoupling seems to be particularly adept at showing how organizations resolve the "transparency paradox" (Bernstein, 2012, p. 209), as although monitoring costs are low it seems particularly difficult to link the release of specific information to the (societal) ends that underpin the norm of transparency. Although he uses a different theoretical framing, Roberts $(2005,2006)$ provides an illustrative example for mean-end decoupling in the realm of information sharing. Within his study on the Canadian Freedom of Information law he found that government agencies actually implemented the law, but that "officials developed internal routines and technologies to minimize its disruptive potential" (Roberts, 2005, p. 1).

The myth of an "imaginary world" (Peled, 2011, p. 5) in which organizations happily and altruistically share their information is untenable. Rather, cases in which organizations share their information appear paradoxical and loaded with politics. Decoupling has been presented as a promising perspective for understanding how organizations successfully "manage transparency" (Schnackenberg \& Tomlinson, 2014, p. 15). The remainder of this study hence follows the research question: How do organizations decouple complying with the norm of transparency from their preferences for secrecy? Or more prosaic: How do organizations perform openwashing?

\section{Method}

\subsection{Research context}

To study the practices of openwashing I turned to the emerging phenomenon of "open data" in and around large city administrations. Some authors have described open data as a social movement concerned with information justice (Johnson, 2014), others as a 
public policy to modernize the administration (Zuiderwijk \& Janssen, 2014), and others as a technological innovation closely linked to the discursive fields of big data (Boyd \& Crawford, 2012) and cloud computing (Bizer, Heath, \& Berners-Lee, 2009). For almost a decade now, city administrations around the world have been continually approached by activists, politicians, entrepreneurs and researchers who expect these administrative bodies to adopt open data policies. Under the broad label of open data, these groups demand that public organizations should make the data sets, which they keep on their servers, available to the public. These data sets would be uploaded to the Internet in machine-readable formats, accessible to anyone and without the need to submit personally identifying information or justify one's usage of the data in order to access it. The data sets would exist under a licensing regime that allows for modification, redistribution and commercial use (Heimstädt, Saunderson, \& Heath, 2014; Schrock, 2016). Due to the fact that digital information can be replicated at zero marginal cost, some authors even argue that Internet-facilitated information disclosure is "true" sharing in contrast to the "pseudo-sharing" associated with phenomena such as collaborative consumption (Belk, 2014, p. 1596). I decided to study the adoption of open data in large cities, as it promised to be fruitful ground for exploring openwashing: On the one side, there are bureaucratic organizations, generally rather secretive and reluctant to change. On the other side, there is a heterogeneous coalition of actors that have the strong conviction that they deserve transparency and who closely monitor the behavior of the administration.

\subsection{Research design and data sources}

My research design is modeled after what Yin (2013) describes as an embedded case study. I decided to study multiple cities that have shown particularly vivid open data activities. In a first stage I used the Open Data Barometer, a ranking created by the non-profit organization World Wide Web Foundation (Davies, 2013), to identify the countries with the highest rate of information disclosure by public organizations. In combination with an evaluation of my potential field access (e.g., contact persons, language barriers), these rankings shaped my decision to study the adoption of open data in London (\#1 in country ranking), New York City (\#2), and Berlin (\#9). I selected these three "most similar" (Seawright \& Gerring, 2008, p. 306) sub-units, not to compare them, but to enlarge the number of information sharing episodes on which 
I can base my analysis, and thereby increase the internal validity of my findings (Pentland, 1999). Within these cities I moved from one episode to the next, venturing back and forth between - inter alia - different city agencies, activist groups and corporate businesses. I did not aim at statistical generalizability but on the identification of rich accounts of openwashing to get an understanding of why and how it takes place (Flyvbjerg, 2006). The data collection took place between June 2014 and October 2015. The period under observation in each of the cities differed slightly across cases: In London and New York City open data roughly entered the local discourse in mid-2009, whereas in Berlin the issue became prevalent in early 2010. The period under observation ended with the completion of data collection in October 2015. This longitudinal research design allowed me to study transparency decoupling as "routinized social practices" that "occur in the sequence of time [and] in repetition" (Reckwitz, 2002, p. 255).

Documents, newspapers, and blogs. Before I entered each of the three cities I consulted official documents, studies, newspaper articles and blog posts about the local open data initiative to get an understanding of the adoption process in general and to find information about episodes of contestation and conflict. For the qualitative researcher, documents have the advantage of being temporarily stable, can also be accessed by other researchers at other times, and are authentic in that they do not originate in research situations but in the context of the actors' day-to-day activities (Yin, 2013). These properties make them particularly useful to form the solid bones of an embedded case study. Table 1 provides an overview of the different documents that I used to inform my analysis.

Table 1: Case study database: documents

\begin{tabular}{lccc}
\hline Types of documents & NYC & London & Berlin \\
\hline Newspaper articles, blog posts & 82 & 36 & 41 \\
Studies, policy documents & 11 & 15 & 18 \\
Other (e.g. Tweets, presentation slides) & 39 & 34 & 36 \\
\hline $\mathbf{\Sigma}$ & $\mathbf{1 3 2}$ & $\mathbf{8 5}$ & $\mathbf{9 5}$ \\
\hline
\end{tabular}


Interviews. To attach the proverbial meat to these bones, I interviewed 79 people who have engaged in the local open data process. On average the interviews lasted 45 minutes. I taped and transcribed each interview. I interviewed not only employees from public organizations who shared some of their data sets, but also members of city governments, various information activists, researchers and private sector employees. This way, not only could I triangulate by data type, but by data source as well (Miles \& Huberman, 1994). During the interviews I started with general questions on the local open data process, followed by questions on contentious issues, which I previously identified in the documents. Sometimes these questions evoked slightly tense situations, as interview partners felt the need to justify their "deviant" acts of decoupling. In retrospect, it was well worth asking these "devil's advocate questions" (Corbin \& Strauss, 1990), as they oftentimes led to in-depth insights on how a perceived norm of openness conflicts with the professional identity and day-today operations of the interviewee. When the interviews revealed new contentious (and non-contentious) episodes or themes, I added information on them to my document database right after the interview. Some of my interview partners suggested and introduced me to other people I should talk to, rendering my theoretical sampling technique both deliberate and emergent. Table 2 gives an overview of the interviews that I conducted in different types of organizations and across cities.

Table 2: Case study database: interviews

\begin{tabular}{|c|c|c|c|}
\hline Types of organizations & NYC & London & Berlin \\
\hline City administration & 5 & 4 & 5 \\
\hline Public service provider & 2 & 2 & 2 \\
\hline City council & 3 & 2 & 1 \\
\hline Advocacy organization & 9 & 8 & 4 \\
\hline Private sector & 3 & 5 & 2 \\
\hline Research institute / think tank & 2 & 8 & 3 \\
\hline Other (e.g. federal institution, unaffiliated) & 2 & 6 & 1 \\
\hline$\sum$ of interviews & 26 & 35 & 18 \\
\hline$\sum$ Interview length in minutes & 1232 & 1103 & 924 \\
\hline$\varnothing$ Interview length in minutes & 49 & 39 & 51 \\
\hline$\sum$ of interviews in total & & 79 & \\
\hline$\sum$ Interview length in minutes total & & 3259 & \\
\hline$\varnothing$ Total interview length in minutes & & 45 & \\
\hline
\end{tabular}




\subsection{Data analysis}

My approach to data analysis followed the typical method for inductive qualitative research in management and organization studies (Corley \& Gioia, 2004; Dacin, Munir, \& Tracey, 2010). In the first step, I collated the various transparency episodes from my interviews, newspaper articles and blog posts into an "event history database“ (Garud \& Rappa, 1994) for each of the three sub-units. This resulted in three narratives on how the concept of open data entered the cities, how it was built up as a demand towards the public organizations, and how they individually responded to this norm of openness. I sought to balance the narratives as much as possible with perspectives from in- and outside the city administration. In the second step, I engaged in open coding across my three sub units. In this process I inductively identified initial concepts and grouped them together into first order categories. I focused my search on contentious episodes in which organizations (ostensibly) gave in to the demands to open up their data sets. For each of the initial concepts I looked for evidence from different data sources within one sub-unit, as well as for evidence across the sub-units to ensure the validity of my initial concepts (Patton, 2001). In the third step, I moved to axial coding, a process in which I related the inductively generated first order categories to one another along higher-order commonalities (Corbin \& Strauss, 1990). This helped me to collapse the first-order categories into fewer second-order themes that levitate between empirical data and theoretical categories. In this process I iteratively ventured back and forth between my empirical data, the emerging theoretical patterns and recent literature. In the fourth step, I grouped the second-order themes into overarching theoretical dimensions that eventually underpinned my theorizing. In the end, three aggregated modes of decoupling emerged from the first-order themes and second-order categories. In the first mode, actors decouple information disclosure from their core operations by being selective. In the second mode they decouple transparency claims from day-to-day operations through bending. In the third mode they orchestrate information in order to decouple. My final data structure is illustrated in Figure 1. Exemplary evidence for the first-order categories is shown in Table 3. 
Figure 1: Data structure

First-order episodes

Second-order practices

Aggregated modes of decoupling

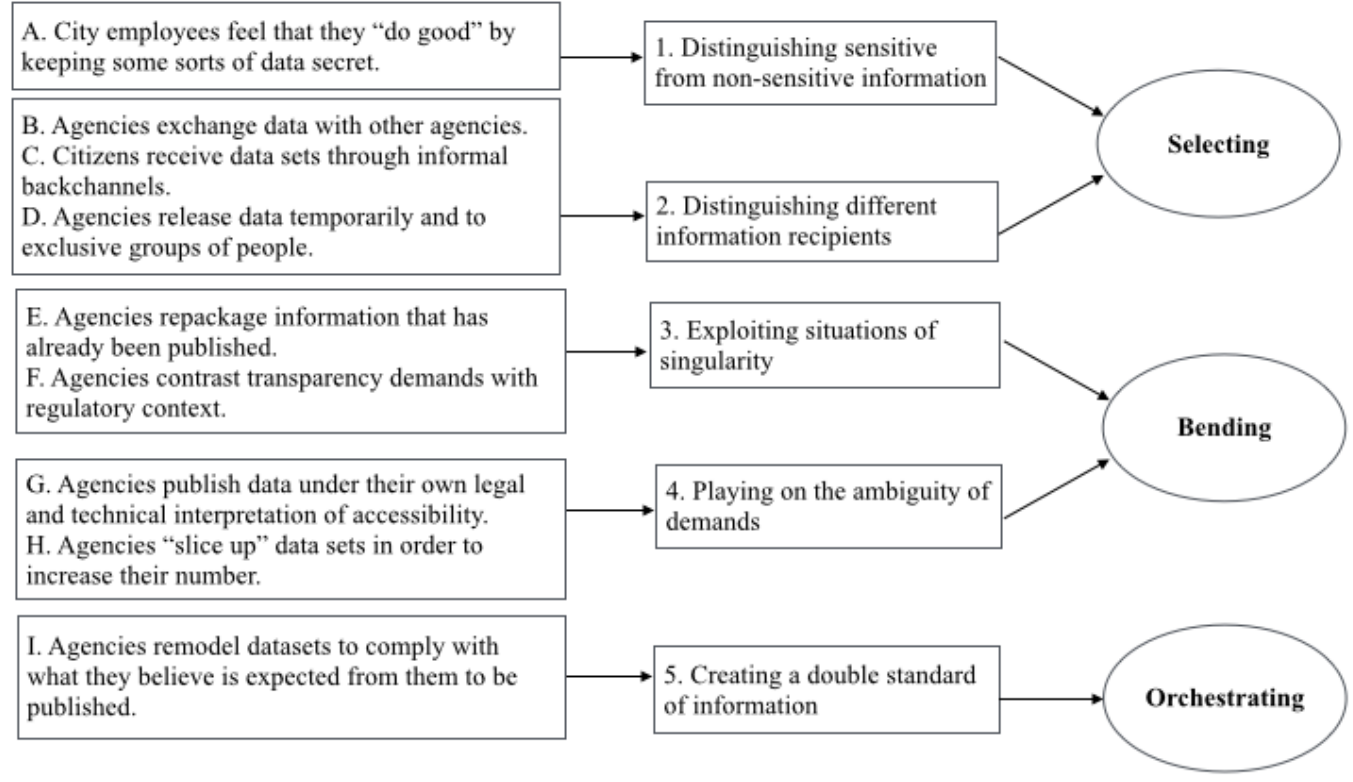

Table 3: Modes, practices, episodes and data

\section{Second-order practices and first-order episodes \\ Representative data}

Mode of decoupling: Selecting

1. Distinguishing sensitive from nonsensitive information.

A. City employees feel that they "do good" by keeping some sorts of data secret.

\section{Distinguishing different information} recipients.

B. Agencies exchange data with other agencies.
A1. "Insurance companies would use those reports to decide how much money they're going to give the people whose house burned down, right?" (Former employee of fire department on holding back certain information)

A2. Several newspaper articles quote politicians who state that the release of granular crime data would be "a risk" and "dangerous" in the hand of the public.

A3. "We are not the owner of this data, we are more of a trustee. We have to take care that this data is not misused". (Public transport employee on schedule data)

B1. An informant describes how city agencies bargain over data sets that are not publicly available: "I don't think that was ever formalized in any way". (Interview with researcher and former city employee) 
C. Activists receive data sets through informal backchannels.

D. Agencies release data temporarily and to exclusive groups of people.

\section{Mode of decoupling: Bending}

\section{Exploiting situations of singularity.}

E. Agencies repackage information that has already been published.

F. Agencies contrast transparency demands with regulatory context.

\section{Playing on the ambiguity of demands.}

G. Agencies publish data under their own legal and technical interpretation of accessibility.
C1. "You would go to their office and you would talk with them and they would give you a floppy disk with the data". (Former information activist describes how he used to obtain public data sets)

C2. "If you're a student you can get through some channels where people will release data to you but not to the general public. That's something that happens a lot, as long as it does not involve profit". (Interview with entry level urban planner)

D2. "This event was in a semi-open format you can say. Participants had to sign non-disclosure agreements". (Employee of taxi agency described an invitationonly event they used to release some new data sets)

E1. "They got advice from branding consultants that they should improve their transparency. They decided, as they are legally obliged to publish certain data sets anyways, to announce their own open data initiative". (Activist on the open data campaign of an energy provider)

F1. "The biggest problem that we had was the data protection act. It actually prohibited what the mayor wanted [note: opening up crime data]. It was our job then to look at how far can we publish the information without breaching the act". (Employee of a police IT department on disclosure of crime data)

F2. "We do take this very seriously, which is why we removed the IDs completely until we can come up with a more robust solution". (Employee of taxi agency on how they needed to modify the data they disclosed to meet privacy regulation)

G1. In response to pressure from politicians and entrepreneurs, a transport provider agrees to open up its train schedule data sets. However in contrast to other agencies in the same city, the data cannot be downloaded, but only accessed through an API (application programming interface). Users who want to access the data need to register with their name.

G2. "We conducted this workshop and the feedback we got was that the way we license our data set is complete crap. [...] However we had good reasons to do it the way we did and I still think it was right". (Interview with civil servant on a data license he codeveloped) 
H. Agencies "slice up" data sets in order to increase their number.

Mode of decoupling: Orchestrating

5. Creating a double standard of information.

I. Agencies remodel data sets to comply with what they believe is expected from them to be published.
H1. "We would take a data set and split it up. Let's say you have a city wide data sets for five years, we would split this up into 25 data sets, so it's one for each borough and five years". (Former city employee on how his team coped with external demand to publish large numbers of data sets)

I1. "Then we detected the first problems. The columns were not consistent... the data was incomplete. That was not very comfortable for the app developers. Then we made several feedback loops with the agencies to make their data comprehensible". (Organizer of a hackathon described how she worked with public organizations on the publication of their data sets)

I2. "At this first hacknight, not much was hacked. We learned that we would need to make our GTFS data (note: transport data format) less complex". (Employee of public transport provider explains how they decided to remodel the data they would publish)

\section{Findings}

Before I engaged in this research project, my understanding of organizational transparency was shaped by success stories of increased accountability and the democratization of knowledge. My impression was that organizations have little strategic room to evade the growing norm of openness and at some point flip from a state of secrecy to one of transparency. However when I began to study the adoption of open data and eventually combined the data from my interviews and documents, a refined understanding began to take shape. Specifically, I identified three modes in which organizations were able to decouple the disclosure of information from their core operations: selecting, bending, and orchestrating.

\subsection{Decoupling by selecting information}

In my explorations of the open data process in NYC, London, and Berlin, I found that organizations managed to decouple their preference for secrecy from their compliance with a norm of transparency by being selective. When selecting, organizations share authentic information, but exclude parts of it or share it with an exclusive audience. The two specific practices that emerged from my data are the distinction between 
sensitive and non-sensitive forms of information, and the distinction between admissible and inadmissible audiences for the information. Both practices allow organizations to avoid disrupting their core processes, as either only information on peripheral processes is published, or information is published only to people that are expected not to use it in a deviant way.

Distinguishing sensitive from profane information. Employees of public organizations attach varying value to the information they use in their day-to-day operations. Some information is considered non-sensitive or peripheral. The employees do not expect that sharing this information would affect them in their continuation of day-to-day activities. Other information they consider more sensitive and they imagine that its disclosure could lead to undesirable consequences. In the case of open data, I oftentimes found that organizational members had to solve the problem of differentiating between sensitive and profane information within certain data sets. Employees of a fire brigade I studied oftentimes faced such a problem: Due to the overall transparency momentum in their city, they felt obliged to publish information on their individual missions. The particular fire brigade I looked at considered themselves part of the wider community of citizens they served. They feared that insurance companies would study the released incident reports in order to find reasons not to pay reimbursements to citizens. To safeguard the community from legal quarreling with well-resourced insurance companies, brigade members would sometimes redact information that they considered not directly related to the incident from the reports before sharing them with the public. By selecting profane from sensitive information, the fire brigade managed to decouple their compliance with a norm of transparency from their core function as a valuable member of the local community. Against the backdrop of the literature on micro politics outlined above, this episode also hints at other motivations for transparency decoupling, e.g. more altruistic motives ("the community") that lie beyond the boundaries of the organization. Across my cases, I found similar practices in fields like crime, transport, and health data. In all of them, organizations selected information that they considered profane and suitable for being shared, e.g. lists with the geographical locations of buildings or trees, from information whose secrecy they considered indispensable for the practical continuation of their day-to-day activities and the 
protection of groups both within and outside of the organization.

Distinguishing different information recipients. Despite the ease of technical reproduction and dissemination of digital information, organizations try to limit the sharing of their information to an exclusive audience. Some recipients of information they consider predictable in a way that their use of the information will not interfere with the organization's core operations. All other potential recipients are considered unpredictable either based on negative experience or simply based on a lack of information. Unlike more standardized forms of disclosure (e.g. reporting on annual expenditures), the broad scope of open data increases organizations' uncertainty about how potential recipients react to the published information. Whilst researching episodes of open data, I learned about other, more covert forms of sharing data. In what was oftentimes referred to as "trusted partner agreements" organizations shared their data sets with other organizations under the condition that the information is not passed along to third parties. These agreements varied in their degree of formalization, but in any case have the effect that the receiving organization (e.g. a research institute) would refrain from publicly demanding the official disclosure of information by the sharing organization (e.g. a city agency). Selectivity of recipients is not only practiced between formal organizations, but between organizations and the community of open data users as well. When speaking to an entry-level urban planner, she remembered how as a college student she regularly contacted employees of planning departments asking for data sets. She could not recall any instances where access to data was denied, however it was granted under the implicit or explicit condition that she would use the data for academic purposes only. In addition to students, journalists, academics, and entrepreneurs took part in open data "hackathons" in each of the three cities. Generally, an open data hackathon is an event at which individuals and organizations meet for one or two days, explore data sets and think about interesting ways to use them for new applications or services. Although these hackathons differed in their format, I learned about events at which the participants were asked to sign "nondisclosure agreements" that restricted them from sharing the data sets with others outside the exclusive group of participants. 


\subsection{Decoupling by bending information}

In some situations selectivity might not be a viable mode to successfully decouple core operations from compliance with a norm of transparency. Across my cases I identified episodes in which organizations managed the balancing act between secrecy and transparency through bending. When bending, organizations share authentic and comprehensive information, but in a form that deviates from the one used within the organization itself. I consider information comprehensive when none of its content has been deliberately withheld. Two distinct practices emerged from my data, the exploitation of situations of singularity and the exploitation of ambiguities in the articulated norms. With both practices, organizations are able to bend the form in which they share their information, keeping a more powerful form for themselves and sharing a less powerful form.

Exploiting situations of singularity. To successfully manage transparency, organizations can use means of timing to balance secrecy against transparency. In the different open data processes that I studied, I identified episodes in which organizations exploited the fact that no other comparable organization in their field had engaged in similar transparency measures. When an organization is the first, or the only one of its kind to share information, it is particularly difficult for external actors to come up with a measure and to evaluate whether transparency has been achieved or not. The general public, represented by the major media outlets, is more interested in some sorts of city data than in others. One of the most sought after domains of data is that on urban crime held by the respective police department. In one of the cities, the mayor utilized this public desire and included the release of granular crime data in his election manifesto. After his success at the ballot box, he ordered the police department to share their databases with the public. After a period of negotiations the police department eventually released aggregated instead of granular crime data through a costly new website and the engagement of additional staff in order to prepare the data sets for release. By pointing to national data protection legislation and their concerns about exposing sensitive individual cases to public scrutiny, the police managed to convince the mayor and the public that they became as transparent as they were able to do. Since they were the first local police department in their country to enact such transparency measures, their situation was 
entirely unprecedented, making it impossible for external stakeholders to question the legitimacy of their information disclosure. Therefore, the police department was able to comply with the significant normative pressure to release information but at the same time remained in control of the granular crime data.

Playing on the ambiguity of demands. The organizations and individuals who create and maintain legitimacy claims for greater transparency have to balance the specificity of their demands with the breadth of organizational types they appeal to. I found that incumbent organizations are able to play on this ambiguity of demands in order to (partially) decouple a facade of transparency from their preference for control over information. In all three cities I found that public transport providers exploited ambiguities within the transparency norm to realize their own technical-legal interpretation of information sharing. Public transport companies are among the most visible and highly debated public organizations in large cities, as problems in their service immediately affect the overall functioning of urban life. They produce and collect tremendous amounts of data on all their operations, and consequently have been pressured for greater transparency from the early days of open data campaigning. In each of the cities, part of what the open data advocates are demanding is that the data sets from all agencies be uploaded to a central open data website. On the website the data is accessible without requiring users to register, and under preselected "open" licenses. In all three cities, however, the public transport providers managed to circumvent these institutionalized transparency measures. Arguing that their data is too voluminous for the existing portals, they made it available through their own APIs. In contrast to the centralized open data website, users must register with their full name in order to access the data. Whilst the public transport providers published under open licenses as well, others have been restricted from commercial use. In these cases, organizations used ambiguities in the open data demands in order to bend the mode of information accessibility towards their preference for control. Other organizations managed to play on demands that measured legitimate transparency by the mere number of disclosed data sets. When open data suddenly became a lively topic in local politics, city agencies in one city received orders from the mayoral office specifying the number of data sets they were required to make accessible during the upcoming month. As finding shareable data 
sets became harder and harder over the months (and in order to keep more sensitive data sets closed), members of the organization began to "game" this quantitative demand by slicing up large longitudinal data sets into smaller ones, e.g. by splitting them up for each individual borough and year. By exploiting the quantitative formulation of the transparency demand, the organization was able to bend the information they shared and prevented having to either release data sets they preferred to keep closed or investing too many additional resources to identify data sets they were not yet aware of.

\subsection{Decoupling by orchestrating information}

Bureaucratic organizations produce information that in form and content sometimes deviates greatly from what outsiders expect it to look like. In these instances, a transparency claim might not be easily settled through selecting or bending information, but requires orchestrated sharing. When orchestrating, organizations share information that is modified in order to fit external expectations about its form and content. The information that is shared has only been produced for the purpose of sharing it. One particular practice emerged from my data on the orchestration of transparency: Organizations craft and publish new versions of existing data sets in order to satisfy what they believe to be the transparency advocates' expectations.

Creating a double standard of information. Even within the same city, the practice of data creation and storage deviates greatly across agencies. To outsiders, some of these practices might appear chaotic and nonprofessional. To decouple their compliance with transparency expectations from the need to restructure their data practices (or alternatively to be shamed for them), organizations may create a double standard for data sets: one for internal use only and another that appears to be for internal use but that is deliberately crafted only for external publication. As publicly funded organizations, museums and archives are exposed to a growing norm of transparency, too. In times of digitalization, external actors (e.g. researchers, other cultural institutions) demand access to the data that was previously confined to databases or paper-based archives. The cultural institutions I spoke to wanted to comply with these demands, yet faced the situation that their internal data structure was in a highly idiosyncratic form and difficult to understand for outsiders. On the 
one hand, they wanted to share their data, but at the same time wanted to avoid potential misinterpretation of the data or inviting criticism of their cryptic way of organizing information. As a solution, the cultural institutions decided to craft entirely new well-structured data sets based on what they believed would be expected from them. They used widely diffused data standards, changed their column headers into lay terms and filled in missing data in their spreadsheets. Across episodes my interviewees stressed that they "learned" how to orchestrate their data sets through feedback from the community of open data users. Orchestrating is thereby not a transitory practice that organizations use until they have learned how to do disclose information in a complete and accurate fashion, but - quite the opposite - a social skill, which organizations have to acquire and which they refine over time.

\section{Discussion}

For this study on openwashing I combined recent literature from transparency studies with established theory on organizational decoupling. On the backdrop of my empirical analysis on open data and openwashing, I am able to make theoretical contributions to both strands of literature. In this section I consider each of them in turn.

\subsection{Contributions to decoupling theory}

In this study, I identified and illustrated three ideal-typical forms of decoupling specific to the practice of information sharing. When selecting, organizations disclose original information in its original format. However, parts of the information or the audience are excluded from disclosure. When bending, organizations release original and complete information, yet manipulate its format in order to retain some control over its representative value. When orchestrating, organizations create new information to be disclosed which modulates the original information, its format and its comprehensiveness. These new forms raise the question about how openwashing practices fit in with established theories and at which points they might expand what we know about decoupling. First, there is policy-practice decoupling in which organizations articulate their intention for structural changes but fall short on actually 
implementing them (Westphal \& Zajac, 2001) ${ }^{2}$. Applied to the issue of transparency, it means that organizations talk about sharing information without actually doing so. The only mode with characteristics that overlap those of policy-practice decoupling is selecting. When being selective, organizations deliberately withhold information in order to protect some core process. In the other two modes, bending and orchestrating, organizations ostensibly "walk their talk." Second, there is mean-end decoupling in which organizations implement structural changes, but ones that fail to achieve the goal that the external actors demand (Bromley \& Powell, 2012). With regards to transparency measures, this translates to situations in which organizations share the information that the external actors demand, however, accessibility to the information does not lead to the desired organizational or societal changes (e.g. increased efficiency, greater accountability, knowledge creation). The only mode with characteristics that overlap those of mean-end decoupling is bending. When bending information, as in the case of the city agency that split up large data sets into smaller ones, the external demand is fulfilled, but the goal (e.g. increasing the amount of information shared) was missed. The struggles around open data have revealed a particular shortcoming of the analytical concept of mean-end decoupling. In the fields of open data, various organizations air the same demand: they want the city administration to share their information. At the same time, these external transparency advocates have different goals and beliefs about why information should be shared. Bending the information they share might help some external actors to reach their goal but not others. For the theory of decoupling, this results in the conclusion that organizations might deliberately try to decouple their means from the goals of organization A, but at the same time might (unintentionally) fulfill the goal of organization B. Third, orchestrated transparency measures fit neither policy-practice nor mean-end decoupling. The information that is shared serves the ends of the external actors, yet the means used are not the ones that have been demanded. This becomes particularly clear in the case of cultural institutions. Journalists and software developers wanted to gain access to the cultural data in order to (playfully) re-use it. At the end of the hackathon, all participants were satisfied with the information that

${ }^{2}$ Recently this perspective has been challenged by authors who argue in favor of the performative nature of communication as prerequisite instead of an alternative to action (Christensen, Morsing, \& Thyssen, 2013). 
was shared with them. However, the data they consumed was meticulously crafted for their amusement. To further understand the dynamics behind orchestrating, the literature on impression management seems particularly useful. Impression management describes efforts to manipulate the perception of a certain audience (Goffman, 1959). Organizations can draw from a repertoire of impression management tactics in order to retain legitimacy towards their relevant environment (Deephouse \& Suchman, 2008; McDonnell \& King, 2013). Many of these tactics involve the regulation of information flows, whereby information that is believed to make a favorable impression is presented and information that is expected to be unsettling is kept closed (Elsbach, 2003; Elsbach \& Sutton, 1992). Whilst all modes of decoupling can be seen as a compromise (Kraatz \& Block, 2008; Pache \& Santos, 2010) or strategic response to external legitimacy claims (Oliver, 1991), orchestrating may allow organizations to absorb a strike and turn it into something favorable. The cultural institutions (chapter 4.3) were facing external demands to make their data sets available. As the initial form of the data sets was incomprehensible to a lay audience, the cultural institutions orchestrated its form to make them easily understandable. By doing so the cultural institutions did not only preserve their internal idiosyncratic system of storing data (decoupling), but at the same time presented themselves as very rational organizations that follow plausible principles of data storage (impression management). As Suchman (1995, p. 582) puts it, these plausible principles of data storage, "mesh both with larger belief systems and with the experienced reality of the audience's daily life". The general public might not question the rationality of a startup company, if it stores its data in an idiosyncratic way. Museums and other cultural institutions however, are much more expected to act as guardians of good archival practice and hence have a preference to "make this impression".

\subsection{Contributions to transparency studies}

Over the last few years, transparency literature has diversified from normative accounts about the benefits and implementation of transparency, towards performative theories of transparency that intend to study what actors actually do when they enact what is perceived as "transparency" (Neyland, 2007). With my study on openwashing I contribute to this literature in two ways. First, I expand on the idea that transparency is mediated through disclosure devices, by pointing at situations 
where these devices are absent. Second, I tackle the transparency-secrecy nexus and make the argument that transparency has to be balanced against, rather than replace secrecy.

With my study I follow the relativist notion that transparency is not a property in itself but that it has to be "enacted" (Albu \& Wehmeier, 2014). Recently, Hansen \& Flyverbom (2015) have studied this enactment of transparency looking at the interplay of human work and mediating technologies. The authors broadly differentiate between "disclosure devices" (2015, p. 872) that produce qualitative knowledge (e.g. due diligence) and others that are about quantitative knowledge production (e.g. rankings, big data). Hansen and Flyverbom focus on the way in which disclosure devices like rankings create different forms of knowledge from shared information. My study contributes to this line of thought by looking at the reactivity of such disclosure devices. In their study on media rankings of law schools, Espeland and Sauder (2007, p. 1) study transparency measures under the auspices of reactivity, "the idea that people change their behavior in reaction to being evaluated, observed, or measured". In my study on open data initiatives, I found that organizations show signs of reactivity not just against the backdrop of rankings with well-known parameters, but also when they anticipate a more vague and diffuse form of evaluation. In these cases we can speak of a "disclosure device void" as the international business scholar speaks of "institutional voids" (Khanna \& Palepu, 2010). Within these disclosure device voids, incumbent organizations have to improvise and anticipate which external actor might evaluate them against which criterion. Further, these incumbents have to decide whether they attach more or less meaning to this evaluation. An illustrative example for how organizations deal with these disclosure device voids is the "trusted partner agreement", identified as a form of decoupling by selecting information (chapter 4.1). The revealing organization feels unable to estimate the effect that a disclosure of information to the general public would have. As a consequence it improvises and only discloses information to actors, which it trusts. Trust thereby at least partly fulfills the function of uncertaintyreduction that a well-known disclosure device (e.g. a ranking) would usually fulfill. Another example from my findings is the way in which the cultural institutions "learn" how to orchestrate their information disclosure in order to receive the 
feedback they desire (the creation of new apps). At first there is no standard on how to disclose the information (disclosure device void), yet after several feedback loops with potential users they are able to disclose their information in a way (e.g. column headers that are understandable for a lay audience) that leads to "codified effects" (Foucault, 2010, p. 62), reactions by app developers and other users that are to some degree predictable and calculable (Weiskopf \& Tobias-Miersch, 2016).

One of the most interesting issues in practice-based transparency studies is the relationship between transparency and secrecy (Albu \& Flyverbom, 2016; Strathern, $2000)^{3}$. With my study I contribute to a few emerging accounts that provide empirical evidence for the necessity of secrecy alongside transparency. In his study on a Chinese mobile phone factory Bernstein (2012, p. 181) comes to the intriguing suggestion that "maintaining observability of workers may counterintuitively reduce their performance by inducing those being observed to conceal their activities through codes and other costly means" and with an organizational design perspective in mind adds that "creating zones of privacy may, under certain conditions, increase performance". On the group level he comes to the conclusion that a moderate degree of privacy supports processes like localized experimentation, distraction avoidance, and continuous improvement. Instead of an industrial plant in Asia I have studied city administrations in the US and Western Europe. The implications of my study expand Bernstein's findings from intra to inter-organizational transparency relations. I have found that if urged to share their data sets with the public, employees of city agencies invest substantive resources to bring scope and form of the data to a point at which they are comfortable sharing it. Although the internal complexity of these agencies makes it particularly difficult to measure their productivity (at least more difficult than an industrial plant), my findings raise concerns whether the costly means of transparency decoupling (e.g. redacting sensitive information, creating proprietary APIs, crafting new data sets) actually result in the cost-reduction and innovation gains that are expected from greater transparency. In my data the secrecy-transparency nexus becomes particularly evident when the police department in one of the cities mobilized significant resources in order to bend its data from granular to aggregated

\footnotetext{
${ }^{3}$ Similarly: light and darkness (Tsoukas, 1997), openness and closeness (Tkacz, 2012), or sharing and withholding (Schor, Fitzmaurice, Carfagna, Attwood-Charles, \& Poteat, 2016).
} 
form. A more through analysis of this case could shed light on the assumption that the mayor's push for greater efficiency of the police through means of transparency had the opposite effect and eventually led to a further accumulation of bureaucratic processes.

Finally, the case selection of this study evokes the question for cultural commonalities or contrasts. The assumption that immediately arises when studying open data in London, New York City and Berlin is that practices of information disclosure might vary along the fault line of New Public Management, which was embraced in UK and the USA beginning in the late 1970s, but which had "cultural, ethical, and political features which did not 'fit' [Germany]" (Pollitt \& Bouckaert, 2011, p. 10). Interestingly, however, my analysis did not reveal strong evidence in support of this assumption and also in other studies there seems to be little evidence "that the core NPM states were way ahead (or behind) in the transparency stakes" (Pollitt \& Bouckaert, 2011, p. 111). Pollitt and Bouckaert (2011, p. 11) provide an avenue to interpret these findings: They argue that from the late 1990s onwards NPM ideas have been layered by a new "wave" of ideas, around concepts such as globalization, governance, networks, partnerships, trust, or transparency. Although open data can therefore still be interpreted as an instrument of NPM (cf. Longo, 2011), it can also be framed as an emancipatory practice, making it more compatible with administrations that have been rather reluctant to NPM.

\section{Conclusions, outlook and implications for management practice}

Organizations increasingly face a growing norm of transparency that challenges their preference for secrecy. Through a decoupling lens, I studied how public organizations solve this problem. I identified three modes in which city agencies decouple their practices of information sharing from the core processes they aim to protect: selecting, bending, and orchestrating. On the one hand, these modes overlap with existing theories of decoupling (policy-practice, mean-end). On the other hand, my findings expand upon existing theory, as they indicate how organizations use decoupling as a tactical tool of impression management. Recent studies on the performance of transparency have engaged with its mediated nature and the disclosure devices at play. In my study I have shown how organizations deal with the absence of 
such anticipatable forms of examination by withholding information they consider a potential threat to their core operations. Finally, and based on these prior findings, I emphasized the importance of institutionalized spaces of secrecy in a world of transparency.

Practices of decoupling have been found across three different cities in different countries. This justifies the assumption that to some extent the results are generalizable to disclosure struggles in other cities as well. Due to the fact that the cities I studied are home to watchdog organizations and a profound culture of information activism, future research could examine whether cities that show different institutional configurations (cf. Aoki, 2001; Hall \& Soskice, 2001) might not only show less information disclosure, but within the instances of disclosure provide more room for transparency decoupling. Building upon my findings, further research could also examine whether other organizational forms draw on different modes of transparency decoupling (Bromley, Hwang, \& Powell, 2013). These differences could be grounded in different sources of legitimacy, as well as the degree of legitimacy they require for organizational survival. For example, what has not been covered in my analysis of city agencies but seems to be a pressing question is how information sharing is enacted by organizations that face conflicting regulatory environments like MNEs operating under different national privacy legislations. Furthermore, it would be interesting to study the relationship between strategic forms of information sharing like openwashing, and forms in which information sharing is unplanned, e.g. whistleblowing. In this regard it seems particularly interesting to study whether openwashing has a chilling effect on the dissatisfaction of employees who consider whistleblowing as a form of "voice" (Hirschman, 1970), or augment their desire for "truth-telling" (Weiskopf \& Willmott, 2013). Finally, longitudinal studies on the process of transparency enactment could provide deeper insights to the dialectic of transparency claims and decoupling practices. This would shed light on the question how the actors who demanded transparency react to the decoupling, e.g. whether and under what conditions they settle or intensify their dispute. A particularly revealing case would be the emissions scandal of the German automaker Volkswagen, to study how consumers, states and the corporation enact transparency in a processual perspective. 
My analysis of transparency decoupling may be informative for managers and employees facing direct or implicit transparency demands, as well as for external stakeholders crafting these norms. My study suggests that there is valuable middle ground between secrecy and transparency. Instead of trying to resist transparency measures for as long as possible, it seems advisable to engage in decoupling activities as they might settle the dispute at a reasonable cost. For employees, my study points at different practical forms in which decoupling can be enacted. For managers, my study suggests signaling to employees the approval of decoupling activities. Consumers, activists, or regulatory bodies on the other hand are advised to express quite specific transparency demands, but on the flipside to grant secrecy in other information domains in order to avoid the creation of (costly) evasive strategies by members of the organizations under pressure.

\section{Acknowledgments}

A previous version of this paper has been presented at the $32^{\text {nd }}$ EGOS Colloquium in Naples and I am grateful for the useful feedback I have received from the convenors and participants of the sub-theme "Organizing in the Shadow of Sharing". Finally, I would also like to thank the guest editor, Thibault Daudigeos, and two anonymous reviewers for their helpful suggestions for developing this paper. The research reported in this manuscript has been funded through a doctoral scholarship granted by the Foundation of German Industry. 


\section{Literature}

Albu, O., \& Flyverbom, M. (2016). Organizational transparency: Conceptualizations, conditions, and consequences. Business \& Society, 1-30.

Albu, O., \& Wehmeier, S. (2014). Organizational transparency and sense-making: The case of Northern Rock. Journal of Public Relations Research, 26(2), 117133.

Aoki, M. (2001). Toward a comparative institutional analysis. Cambridge, MA: MIT Press.

Bauer, R., \& Gegenhuber, T. (2015). Crowdsourcing: Global search and the twisted roles of consumers and producers. Organization, 22(5), 661-681.

Belk, R. (2014). You are what you can access: Sharing and collaborative consumption online. Journal of Business Research, 67(8), 1595-1600.

Bernstein, E. (2016). Making transparency transparent: The evolution of observation in management theory. Academy of Management Annals.

Bernstein, E. S. (2012). The transparency paradox: A role for privacy in organizational learning and operational control. Administrative Science Quarterly, 57(2), 181-216.

Birchall, C. (2011). Introduction to "secrecy and transparency": The politics of opacity and openness. Theory, Culture \& Society, 28(7-8), 7-25.

Birchall, C. (2014). Radical transparency? Cultural Studies $\leftrightarrow$ Critical Methodologies, 14(1), 77-88.

Birkinshaw, J. (2006). Transparency as a human right. In C. Hood \& D. Heald (Eds.), Transparency: The key to better governance? (pp. 47-57). Oxford: Oxford University Press. 
Bizer, C., Heath, T., \& Berners-Lee, T. (2009). Linked data-the story so far. In Semantic services, interoperability and web applications: Emerging concepts (pp. 205-227).

Boxenbaum, E., \& Jonsson, S. (2008). Isomorphism, diffusion and decoupling. In R. Greenwood, C. Oliver, R. Suddaby, \& K. Sahlin-Andersson (Eds.), The SAGE handbook of organizational institutionalism (pp. 78-98). Thousand Oaks, CA: SAGE Publications.

Boyd, D., \& Crawford, K. (2012). Critical questions for big data: Provocations for a cultural, technological, and scholarly phenomenon. Information, Communication \& Society, 15(5), 662-679.

Bromley, P., Hwang, H., \& Powell, W. W. (2013). Decoupling revisited: Common pressures, divergent strategies in the U. S. nonprofit sector. $M @ n @ g e m e n t$, 15(5), 469-501.

Bromley, P., \& Powell, W. W. (2012). From smoke and mirrors to walking the talk: Decoupling in the contemporary world. The Academy of Management Annals, 6(1), 483-530.

Burns, T. (1961). Micropolitics: Mechanisms of institutional change. Administrative Science Quarterly, 6(3), 257-281.

Chesbrough, H. (2006). Open innovation: The new imperative for creating and profiting from technology. Boston, MA: Harvard Business Press.

Christensen, L. T., Morsing, M., \& Thyssen, O. (2013). CSR as aspirational talk. Organization, 20(3), 372-393. 
Corbin, J., \& Strauss, A. (1990). Basics of qualitative research: Techniques and procedures for developing grounded theory. Thousand Oaks, CA: SAGE Publications.

Corley, K. G., \& Gioia, D. A. (2004). Identity ambiguity and change in the wake of a corporate spin-off. Administrative Science Quarterly, 49(2), 173-208.

Costas, J., \& Grey, C. (2014). Bringing secrecy into the open: Towards a theorization of the social processes of organizational secrecy. Organization Studies, 35(10), 1423-1447.

Crozier, M., \& Friedberg, E. (1980). Actors and systems: The politics of collective action. Chicago, IL: University of Chicago Press.

Curtin, D., \& Meijer, A. J. (2006). Does transparency strengthen legitimacy? Information Polity, 11(2), 109-122.

Dacin, M. T., Munir, K., \& Tracey, P. (2010). Formal dining at Cambridge colleges: Linking ritual performance and institutional maintenance. Academy of Management Journal, 53(6), 1393-1418.

Davies, T. (2013). Open data barometer 2013 global report. London: The World Wide Web Foundation.

Deephouse, D. L., \& Suchman, M. (2008). Legitimacy in organizational institutionalism. In R. Greenwood, C. Oliver, K. Sahlin, \& R. Suddaby (Eds.), The SAGE handbook of organizational institutionalism (pp. 49-77). Thousand Oaks, CA: SAGE Publications.

Drucker, S. J., \& Gumpert, G. (2007). Through the looking glass: Illusions of transparency and the cult of information. Journal of Management Development, 26(5), 493-498. 
Elsbach, K. (2003). Organizational perception management. Research in Organizational Behavior, 25, 297-332.

Elsbach, K., \& Sutton, R. I. (1992). Acquiring organizational legitimacy through illegitimate actions: A marriage of institutional and impression management theories. Academy of Management Journal, 35(4), 699-738.

Espeland, W. N., \& Sauder, M. (2007). Rankings and reactivity: How public measures recreate social worlds. American Journal of Sociology, 113(1), 1-40.

Flyvbjerg, B. (2006). Five misunderstandings about case-study research. Qualitative Inquiry, 12(2), 219-245.

Foucault, M. (2010). The government of self and others: Lectures at the Collège de France, 1982-1983. New York, NY: Picador/Palgrave Macmillan.

Garsten, C., \& Montoya, M. (Eds.). (2008). Transparency in a new global order: Unveiling organizational visions. Northampton, MA: Edward Elgar.

Garud, R., \& Rappa, M. (1994). A socio-cognitive model of technology evolution: The case of Cochlear implants. Organization Science, 5(3), 344-362.

Goffman, E. (1959). The presentation of self in everyday life. New York, NY: Anchor Books.

Hall, P. A., \& Soskice, D. W. (Eds.). (2001). Varieties of capitalism: the institutional foundations of comparative advantage. Oxford [England]; New York: Oxford University Press.

Hansen, H. K., Christensen, L. T., \& Flyverbom, M. (2015). Introduction: Logics of transparency in late modernity. Paradoxes, mediation and governance. European Journal of Social Theory, 18(2), 117-131. 
Hansen, H. K., \& Flyverbom, M. (2015). The politics of transparency and the calibration of knowledge in the digital age. Organization, 22(6), 872-889.

Heimstädt, M. (2015). Societal self-observation in the time of datafication. Cybernetics and Human Knowing, 22(4), 57-73.

Heimstädt, M., Saunderson, F., \& Heath, T. (2014). From toddler to teen: Growth of an open data ecosystem. JeDEM - eJournal of eDemocracy and Open Government, 6(2), 123-135.

Hirsch, P. M., \& Levin, D. Z. (1999). Umbrella advocates versus validity police: A life-cycle model. Organization Science, 10(2), 199-212.

Hirschman, A. O. (1970). Exit, voice, and loyalty: Responses to decline in firms, organizations, and states. Cambridge, MA: Harvard University Press.

Hood, C. (2006). Transparency in historical perspective. In C. Hood \& D. Heald (Eds.), Transparency: The key to better governance? (pp. 3-23). Oxford: Oxford University Press.

Hood, C. (2007). What happens when transparency meets blame-avoidance? Public Management Review, 9(2), 191-210.

Hood, C., \& Heald, D. (Eds.). (2006). Transparency: The key to better governance. Oxford: Oxford University Press.

Johnson, J. A. (2014). From open data to information justice. Ethics and Information Technology, 16(4), 263-274.

Khanna, T., \& Palepu, K. G. (2010). Winning in emerging markets: A road map for strategy and execution. Boston, MA: Harvard Business Press. 
Kraatz, M. S., \& Block, E. S. (2008). Organizational implications of institutional pluralism. In The SAGE handbook of organizational institutionalism (Vol. 840, pp. 243-275). Thousand Oaks, CA: SAGE Publications.

Küpper, W., \& Ortmann, G. (1988). Mikropolitik: Rationalität, Macht und Spiele in Organisationen. Opladen: Westdeutscher Verlag.

Laamanen, T., Pfeffer, J., Rong, K., \& Van De Ven, A. H. (2016). Special issue call for papers on: Business models, ecosystems, and society in the sharing economy. Academy of Management Discoveries, 2(2), 218-221.

Longo, J. (2011). \#Opendata: Digital-era governance thoroughbred or new public management trojan horse? Public Policy and Governance Review, 2(2).

Lord, K. M. (2007). The perils and promise of global transparency: Why the information revolution may not lead to security, democracy, or peace. Albany, NY: SUNY Press.

McDonnell, M.-H., \& King, B. (2013). Keeping up appearances: Reputational threat and impression management after social movement boycotts. Administrative Science Quarterly, 58(3), 387-419.

Meyer, J. W., \& Rowan, B. (1977). Institutionalized organizations: Formal structure as myth and ceremony. American Journal of Sociology, 83(2), 340-363.

Miles, M. B., \& Huberman, A. M. (1994). Qualitative data analysis: A methods sourcebook. Thousand Oaks, CA: SAGE Publications.

Neyland, D. (2007). Achieving transparency: The visible, invisible and divisible in academic accountability networks. Organization, 14(4), 499-516.

Oliver, C. (1991). Strategic responses to institutional processes. Academy of Management Review, 16(1), 145-179. 
Pache, A.-C., \& Santos, F. (2010). When worlds collide: The internal dynamics of organizational responses to conflicting institutional demands. Academy of Management Review, 35(3), 455-476.

Patton, M. Q. (2001). Qualitative research \& evaluation methods. Thousand Oaks, CA: SAGE Publications.

Peled, A. (2011). When transparency and collaboration collide: The USA open data program. Journal of the American Society for Information Science and Technology, 62(11), 2085-2094.

Pentland, B. T. (1999). Building process theory with narrative: From description to explanation. Academy of Management Review, 24(4), 711-724.

Pollitt, C., \& Bouckaert, G. (2011). Public management reform: A comparative analysis (3rd ed.). Oxford: Oxford University Press.

Powell, W. W., \& Colyvas, J. A. (2008). Microfoundations of institutional theory. In The SAGE handbook of organizational institutionalism (pp. 276-298). Thousand Oaks, CA: SAGE Publications.

Reckwitz, A. (2002). Toward a theory of social practices: A development in culturalist theorizing. European Journal of Social Theory, 5(2), 243-263.

Rifkin, J. (2015). The zero marginal cost society: The internet of things, the collaborative commons, and the eclipse of capitalism. New York, NY: St. Martin's Griffin.

Ringel, L. (2014). Organizational responses to expectations of transparency. 30th EGOS Colloquium.

Roberts, A. (2005). Spin control and freedom of information: Lessons for the United Kingdom from Canada. Public Administration, 83(1), 1-23. 
Roberts, A. (2006). Dashed expectations: Governmental adaptation to transparency rules. In C. Hood \& D. Heald (Eds.), Transparency: The key to better governance? (pp. 106-125). Oxford: Oxford University Press.

Schnackenberg, A. K., \& Tomlinson, E. C. (2014). Organizational transparency: A new perspective on managing trust in organization-stakeholder relationships. Journal of Management, n.p.

Schor, J. B., Fitzmaurice, C., Carfagna, L. B., Attwood-Charles, W., \& Poteat, E. D. (2016). Paradoxes of openness and distinction in the sharing economy. Poetics, 54, 66-81.

Schrock, A. R. (2016). Civic hacking as data activism and advocacy: A history from publicity to open government data. New Media \& Society, 18(4), 581-599.

Scott, W. R. (1995). Institutions and organizations. Thousand Oaks, CA: SAGE Publications.

Seawright, J., \& Gerring, J. (2008). Case selection techniques in case study research: A menu of qualitative and quantitative options. Political Research Quarterly, 61(2), 294-308.

Strathern, M. (2000). The tyranny of transparency. British Educational Research Journal, 26(3), 309-321.

Suchman, M. C. (1995). Managing legitimacy: Strategic and institutional approaches. Academy of Management Review, 20(3), 571-610.

Tallberg, J. (2016). Transparency and openness. In J. Katz Cogan, I. Hurt, \& I. Johnstone (Eds.), Oxford handbook of international organizations. Oxford: Oxford University Press.

Thompson, J. B. (2005). The new visibility. Theory, Culture \& Society, 22(6), 31-51. 
Tilcsik, A. (2010). From ritual to reality: Demography, ideology, and decoupling in a post-communist government agency. Academy of Management Journal, 53(6), 1474-1498.

Tkacz, N. (2012). From open source to open government: A critique of open politics. Ephemera, 12(4), 386-405.

Tsoukas, H. (1997). The tyranny of light. Futures, 29(9), 827-843.

Weber, M. (1978). Economy and society: An outline of interpretive sociology. Berkeley, CA: University of California Press.

Wehmeier, S., \& Raaz, O. (2012). Transparency matters: The concept of organizational transparency in the academic discourse. Public Relations Inquiry, 1(3), 337-366.

Weiskopf, R., \& Tobias-Miersch, Y. (2016). Whistleblowing, parrhesia and the contestation of truth in the workplace. Organization Studies, 37(11), 16211640.

Weiskopf, R., \& Willmott, H. (2013). Ethics as critical practice: The "Pentagon Papers", deciding responsibly, truth-telling, and the unsettling of organizational morality. Organization Studies, 34(4), 469-493.

Westphal, J. D., \& Zajac, E. J. (2001). Decoupling policy from practice: The case of stock repurchase programs. Administrative Science Quarterly, 46(2), 202.

Yin, R. K. (2013). Case study research: Design and methods. Thousand Oaks, CA: SAGE Publications.

Zhu, F., \& Iansiti, M. (2012). Entry into platform-based markets. Strategic Management Journal, 33(1), 88-106. 
Zuiderwijk, A., \& Janssen, M. (2014). Open data policies, their implementation and impact: A framework for comparison. Government Information Quarterly, 31(1), 17-29. 